\title{
Business Process Reengineering in The Construction Of Precast Timber Frame Buildings
}

\author{
Mirsad Kararić, M.Sc. M.Eng, Civ.Eng. \\ Libra projekt Ltd \\ e-mail:mkararic@libraprojekt.hr
}

\author{
Ivica Završki, Prof., Ph.D. \\ Faculty of Civil Engineering, Zagreb \\ Department of Construction Management \\ and Economics \\ e-mail: zavrski@grad.hr
}

DOI 10.5592/otmcj.2012.1.8 Research paper

THIS STUDY DEALS WITH THE ISSUE OF OPTIMISING THE WORK PROCESSES OF A COMPANY BUILDING PRECAST TIMBER FRAME STRUCTURES, primarily intended for the long-term stay of people, such as: family houses, kindergartens, hotels etc. The issue is considered within the framework of the business process reengineering of the company. At the end a proposal is given for the optimal organizational structure of the company.

The basis of the study is found in the importance of precast building in the contemporary way of life. The increasing demands of energy and ecology, the need to reduce the stress of those involved in the construction process, the pace of building etc., are only some of the reasons which favour the construction of precast, timber frame buildings. In this context, we are referring exclusively to construction using precast elements (panel construction) with the maximum degree of readiness, which at the same time enables quick and good quality construction. However, the high level of readiness of the panels is also linked to an increase in the risks of production (the occurrence of faults and their consequences) which necessarily requires detailed analysis of the organizational system of the company. This study attempts to direct consideration towards the optimal organizational structure of a company dealing with constructing precast timber frame buildings, which on the one hand ensures production of the quality required, and on the other finds an optimal solution to the question of the organization of production, social relationships within the company, worker satisfaction etc. In the end this should result in optimization (increase) of profits.

\section{Introduction}

\subsection{The History of Precast Building}

Precast building has always been a challenge in terms of the attempt to build buildings, above all, more quickly, whilst at the same time meet- ing all the conditions of good quality construction. This paper deals with the precast mode of construction using a timber frame, of the panel type, suitable for buildings with 3-4 storeys above ground. Therefore, in the text below, the term "precast building" will be used to refer to precisely this 
type of building. These are above all family houses, and various buildings for public use, such as: kindergartens, health centres, and other health institutions, housing for the elderly, small hotels etc.

We can trace the beginnings of precast building right back to Leonardo Da Vinci, who developed the first precast panel type structure in 1494, known as the Casa Mutabile. The further development of precast building has been linked over time with various social development. This primarily refers to major migratory movements and the need for buildings which are lighter, can be transported and which may be set up and demolished by any workers in the field or by the owners themselves. A typical example was the American gold rush in the middle of the 19th century, when, for the first time the mass production came about of light weight precast housing units, known as "ready-made houses," mainly the work of George Snow.

Precast building lost popularity after the Second World War, when poor quality barracks were built throughout Europe as emergency housing. Positive trends have only been present in Europe in the last 40 or so years, thanks to the development of new methods and systems of construction.

The trend of development of precast building began in Europe at the beginning of the twentieth century. In Germany at that time, the first form of precast building using a panel system appeared in as early as 1919, when Walter Gropius founded the "Bauhaus" architectural school in Weimar. The pioneer of precast houses in Germany was Konrad Wachsmann in Niesky, who founded the first factory for production of precast buildings at the beginning of the 2oth century. An interesting point is that Albert Einstein built this type of precast house for himself near Berlin even before 1940.

\subsection{The Importance of and an Explanation of the Study}

Precast buildings have long held an appropriate place in civil engineering in developed countries, within the framework of the limitations of the buildings mentioned above. From the 1970's right up to 2005 the construction of this type of buildings increased in Austria for example by almost 15 times (from 400 to 5,600 ) and it has remained at that level since (Östereicher Fertighausverband). It is similar in the remainder of Western Europe, in view of the similar tradition in Germany, France and Italy etc. The Association of German Premanufactured Building Manufacturers mentions an increase in production in 2009 regardless of the crisis and a further significant increase in 2010 (Bundesverband, 2010). In those parts of Europe which have relatively recently changed their social order, the growth in precast building is significantly greater and at the moment it is a rapidly growing market. From this we can conclude that precast building has become an indispensable construction method. The reason for this may be found in the speed of construction, the rounded and complete financial investment, the reduction in stress during construction, the greater use of space, the more favourable form of building in terms of energy use, the dynamics of the labour market etc. For all these reasons precast building is a significant and important part of the construction industry, which lends support to this research.

\subsection{The Purpose and Aims of the Research}

For a company dealing in precast building to be considered successful, it must have a satisfactory volume of agreed business, it must build without faults in production, have controlled expenditure and satisfactory profits.
The volume of agreed business is the matter of the marketing solutions and the marketing skills of the company. Faults in production are a factor which can have the greatest influence on the results of the project. To avoid this, the process of monitoring and control must be well designed. However, production without faults still does not mean that the company will be successful. This is the result of many elements, of which, in the context of this research, we will mention the organization of production, the organization of storage and delivery of goods and materials, the productivity and commitment of the work force, vertical and horizontal communication in the company etc. These are parameters whose optimization can have a significant impact on expenditure.

Almost no research has been done into all of this, whether in the form of scientific studies or professional articles. The area of precast building is a closed discipline, in which the participants jealously guard the knowledge they have gained. Research has tried to define the influential factors for the success of a company, such as: optimizing the organizational structure, business process reengineering, monitoring and control systems, only partial monitoring of business risks, the response of the company to the dynamic movements of the market etc. The main aims of this study are:

1.to review the scientific and professional literature in this field

2. to identify the process in practice through a case study

3.to identify the influential factors for the problem set

4. On the basis of the conclusion drawn from the above, to make a proposal to optimize the business processes of the precast building company on the basis of reengineering. 


\section{Methodology}

The research (Kararić, 2011) from which this article is drawn deals in more detail with the problems of precast building and the areas that should be considered while resolving these problems. In the systematization of the data, an overview and analysis were undertaken of the available literature and published articles, as well as the author's personal knowledge. During the research it came to light that the best way of systematizing and presenting the data and drawing a conclusion was according to the organization chart below.

Methodology of the research
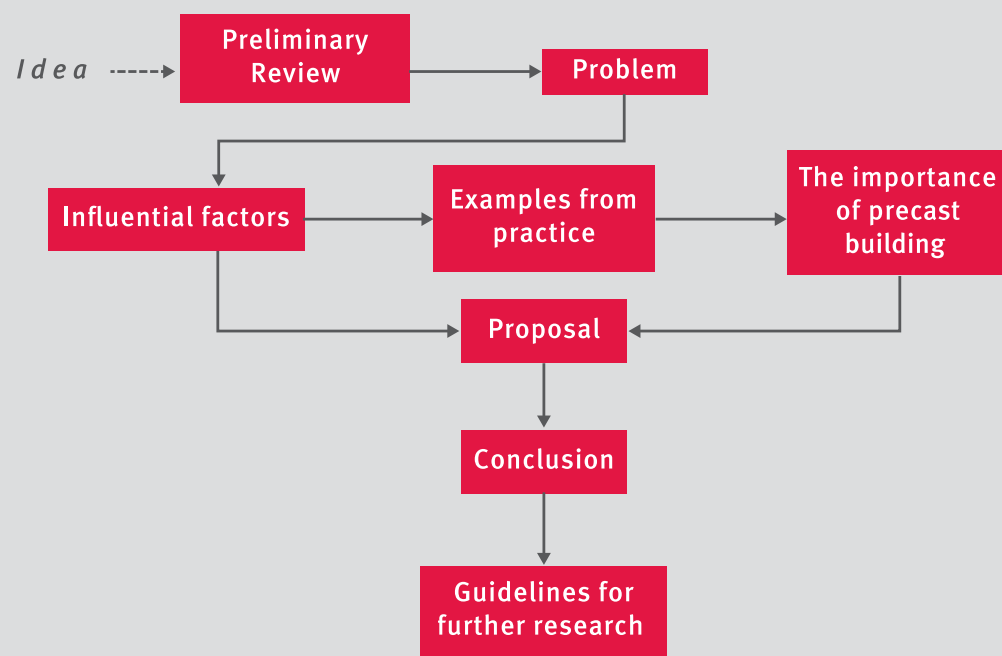

Figure 1: The Methodology of Creating the Study

\subsection{Limitations of the research}

Precast buildings with timber frames differ in terms of the type of load bearing construction and according to the level of readiness of the precast elements. According to the load-bearing structure, they may be built using of timber panel walls (or similar elements of solid timber) or as a skeletal structure made of verticals and flanges, as shown in Figure 2. In both cases this is the "panel" form of construction, which is the subject of this article.

The level of readiness of the precast buildings depends on the obligations agreed. The contractor always tries to attain the maximum possible level of readiness in production in order to reduce the costs of construction, but thereby increases the risk of the occurrence of faults in production. Therefore in this study we consider the "panel" manner of building with the maximum degree of readiness.

Furthermore, the subject of this study is a consideration of the organizational problems of the company, the design of the organizational structure and busi- al or energy (heat insulation) solutions. This study considers the individual approach to construction, which assumes an individual approach to the customer, and the offer and construction of each building according to an independent architectural solution.

\subsection{Influential factors and the field of research}

A business organization is only a subsystem of the wider or narrower social or business community, and as such is subject to all the influences and risks which stem from that. The ability of an organization to survive is in fact the ability to adapt to those influences and find a good response. The influences differ in character and intensity: from sociological relationships through interaction with local and state structures, right up to the market itself and the obligation to ensure a sufficient level of income. The influential factors given below are related to the company as a separate organizational system. Here the relationships with the wider social community should never be forgotten. During the research into the problem it emerged that the following factors influence the solution: the organizational structure as a function of the volume of production, the size of the company and the quality of its operations, the globalization process, outsourcing, the virtual organization, TQM (Top Quality Management), benchmarking, and reengineering.

those factors are ignored which have no effect on this, such as some architectur-

UPPER BEAM

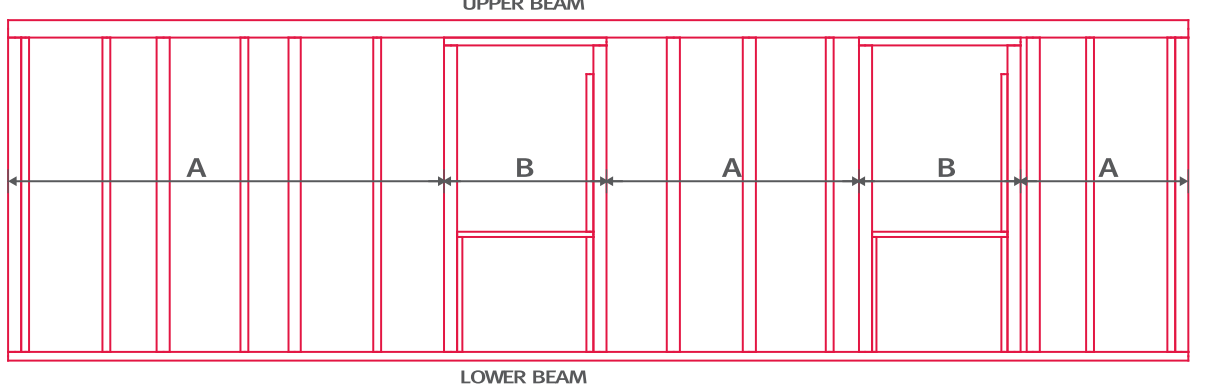

A: Panel with ribs; B: Opening in the wall

Figure 2: An Example of Construction of an External Wall with Openings 


\section{Case study}

The case study includes three companies: two from Germany and one from Croatia. All the data presented in the case study are the result of observations by the author himself, interviews with the heads and owners, or data published in public media. In the text below, the organizations will be denoted as A, B and C.

\subsection{Organization A}

Organization A operates in Germany, with a tradition of c. 25 years. It fosters the panel construction method and strives for the maximum possible degree of readiness and "turnkey" projects. The company has an individual approach to its clients, and has c. 25 permanent employees. It consists of three organizational units: the production hall, the building site and the management structure. The production process has externalized/outsourced activities, such as for example the creation of roofing structure, external and internal joinery etc. The processes that take place on the building site are managed by the company, but most of the work is outsourced. This primarily refers to the creation of the foundations, but also assembly etc. The company has retained the process of providing the necessary vehicles and machinery, connections etc. The core process is the technical preparation, which acts as a separate unit. All units have twoway communication with each other. The strengths and weaknesses of this organization are given below.

Strengths: many years' tradition and image, a network of sales agents, material resources for production (machinery and tools), IT equipping and solutions, their own technology, some technical solutions are patented, client orientation and tendency to innovation.

Weaknesses: there are informal groups within the organization, there is no clearly defined management system, the majority owner controls all the processes in the organization, there is no feedback from the assembly, poor quality linkage of technical preparation - production - assembly - technical preparation, poor quality connections between building site production, faults in production, relationships with sales agents, relationships with employees (workers).

\subsection{Organization B}

Organization B is also on the German market. The company has a total of 18 employees with annual turnover of c. 12 million $€$. The organization has a similar structure to organization $A$. The difference is seen in the additionally outsourced production of precast elements, whereby Organization B achieves a greater volume of production, and accordingly higher annual income.

The management structure is similar to the previous case, but differs in that a separate process exists for monitoring and control.

Strengths: sales network - their own and through a network of sales agents, material resources for production (machines and tools), equipped with IT solutions, orientation to clients - the organization has an individual approach to construction, a tendency for innovation, the ability of top management to make bold moves - innovation and inventiveness.

Weaknesses: lack of tradition and branding, high costs of depreciation due to procurement of necessary machines and tools, the company does not have great technical or technological knowledge, lack of clear vision of division of work and tasks, the system is managed by one owner who controls all the processes in the organization, the overall working climate in the organization does not encourage worker commitment, lack of feedback - production and assembly, poor quality links between individual parts of realization of projects, control of the loading process, faults in production, poor quality relationship with sales agents.

\subsection{Organization C}

This is a very small Croatian company organized on the basis of "everyoneeverything" which is not a basis for serious consideration. It is mentioned more as an example of possible performance levels and the accompanying competences rather than as an example of a serious organizational structure. The strengths and weaknesses of this system are given below: Strengths: sales exclusively by internet, flexibility and adaptability, the desire to learn, technical preparation - cooperation with another company in preparing workshop designs, good relationship between owner and employees, teamwork - all employees are a single team.

Weaknesses: technical preparation the company does not have its own technical equipment, lack of professional technical staff, faults in production, lack of elaborated company strategy or planned cycle, insufficient material means for more serious approach to production, poor material equipment - lack of appropriate machinery and tools.

\section{Important characteristics of systems for construction of precast buildlings}

Some of the main characteristics of precast building are: the possibility of building individual elements of buildings on CNC machines, the geometrical complexity of construction, timber as a relatively light material, differing levels of readiness of precast elements, fast pace of building, more favourable ratio of price of transport and total price of structure, strong influence of the price of machinery for assembly in relation to success of 
project, disproportionally high costs in the case of faults in production, very professional work force, whose knowledge is gained primarily by experience.

Apart from these general characteristics, the key points of production of the finished elements are mentioned. The key points of production are activities which have an important influence on the final quality of the product, and on the final success of the project. An overview of the key points is given below, classified according to the specific location:

\section{Key points of production in the hall}

- Good quality workshop plans

- Readiness of head of production regarding workshop plans

- Prepared materials and connectors at all working points

- The process of monitoring and control during production

Key points of preparation and assembly at the building site

In parallel with the production process in the hall, it is necessary to undertake preparations for transport and assembly of the structure. Some of these activities are connected to the production process in the hall and some are independent of it. These are:

- reporting on control of production in the hall

- loading plan and assembly plan with a list of necessary machines and vehicles

- plan for the use of the work force for assembling the building

- report on provision of connections to infrastructure on the building site

- the readiness of preparation work

- report on control of work done

- check list of all necessary materials for assembly

- report on possibility of access by machinery and vehicles to assembly site

- if necessary, a plan of the assembly dynamics of the precast elements of the building

- analysis of risk points of assembly, and activities that need to be undertaken if a problem arises

\subsection{Subjects of the}

organizational structure of the construction company dealing with precast houses

The term subjects, for the purposes of this study, implies the basic components of the organizational structure, regardless whether in production or management. These subjects may be divided into three basic groups.

\subsection{The subjects of the}

organizational structure related to production - the production hall

Production of precast elements is organized in a hall at the "working points" planned for that purpose. The following production subjects are defined depending on the working points:

- wall elements: internal walls, external walls, gables and temporary storage

> ceiling panels: panels, panels with visible beams, temporary storage

- roof: roof elements, dormers, temporary storage

- balconies and railings, staircases, façade, joinery, installations, central storage

An integral part of subjects of production in the hall are the subjects within the management structure in production. Each working point is managed by a manager. Depending on the size of the company, that is, its production capacity, one working point may imply several positions for production of the same elements, e.g. wall panels. Apart from the production working points, there are also the managers of the procurement process, monitoring and control and the process of technical preparations.
4.12 The subjects of the organizational structure related to activities on the building site The subjects on the building site given below are both the subjects of the management structure and the subjects of the construction work. The subjects are based mainly on groups or types of work which are characteristic of the construction of these buildings. These are: construction of the foundations, assembly of precast elements, organization of necessary vehicles and machinery, installation work, façade work, finishing work, the procurement process, infrastructure and provision of connections, the process of monitoring and control, and the management of all processes on the building site.

\subsection{The subjects of the} organizational structure related to the top management of the company

The central subjects of the management structure of the company for production of precast buildings are the project determinants of the company. The project system of a company like this is in many ways specific in relation to other project systems, and therefore it has an important effect on the other subjects. The basic determinants of the management structure of the company are given in the figure below.

\subsection{Key factors for success}

Precast construction has its own specific characteristics, some of which have already been presented. The critical activities in the realization of a project stem precisely from those specific characteristics. We can analyse them through the project realization phase by identifying the critical activities for each individual phase.

\section{The Sales Phase}

- The value of the sale (agreed work) 
Provision of investment (loan) funding as logistical assistance to the client

\section{The Production Phase}

- Elaboration of the workshop plans including all necessary materials

- Preparation of necessary materials and connectors

- Laying down the lower flanges

- Alignment of the production plan with the plan for laying down elements in the hall

- Drawing up plans for loading and assembly

- Correct details of panel fitting

- Quality control of finished elements

\section{The Construction Site Phase}

- Alignment of the production plan with plan of construction of foundations

- Preparation work and organization of transport, which covers the following points:

- Final control of production

- Plans for loading and assembly

- Timely provision of vehicles and machinery for assembly

- Provision of specialized transport

- Organization of building site for access of machinery and vehicles

Alignment and success of all the above critical activities are a basic condition for the success of the entire project or production.

\section{Business Process Reengineering (BPR) in precast building}

Business process reengineering of a company fundamentally changes the work methods and the approach to problem solving. At root, reengineering had four determinants. They are: fundamental rethinking, and radical redesign of business processes to achieve dramatic improvements (Thom, 2001). The dramatic quality stems from the required level of improvement, which moves from $30 \%$ upwards. The concept was born at the end of the 1980's and the beginning of the 1990's, by transfer of the organizational focus from function to an approach to the process. Apart from the basic determinants of reengineering already mentioned, other important features are also: radical changes in thinking, orientation towards the "core business", a radical change in the approach to problem solving, introduction of other methods and organizations, inventiveness, innovation, creativity, dynamism, a new start and high risk.

So, for the management board to decide to initiate BPR, they must be aware of the need for a fundamental change in the way they operate and be aware of the high risk the company will be exposed to. The BPR development cycle is shown in the Figure below:
The first four elements in this series (idea, analysis, decision, and team) come under the area of the authority of the company's management board. After founding a team, the authority over the process is taken on by the team, with regular reporting to the management, whilst the management itself has the role of monitoring the process.

The following people should be on the team to implement the BPR process in an organization dealing in precast timber frame building:

- the head of production of precast elements

the head of business processes on the building site

the head of technical preparation

the head of procurement

the main sales agent

the head of human resources.

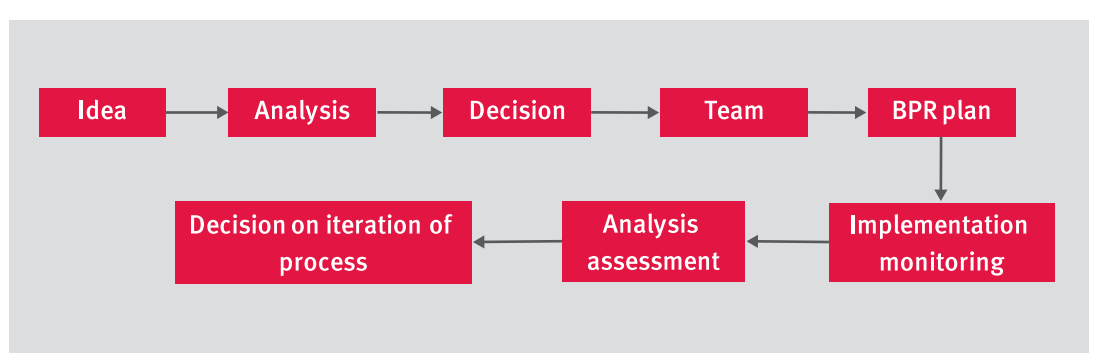

Figure 3: The BPR Development Cycle

In consideration of the existing status and planning the main determinants for future development, the aim must be defined and the reason for initiating the improvement process.

Aim: To improve the production process by a minimal percentage of $30 \%$.

Reason: An unsatisfactory position on the market in relation to competitors, but also lagging behind in a technological and technical sense. The reason may also be the desire to improve the position on the market or preventive activities as a response to future difficulties.
The consultant team members (external members):

- the external commissioner

$\checkmark$ the client

a professional technical associate

After it has been selected and founded, and after it has received all the necessary authority from the company management, the team adopts a plan for implementation of BPR. The main points of the plan are shown in the scheme below: 


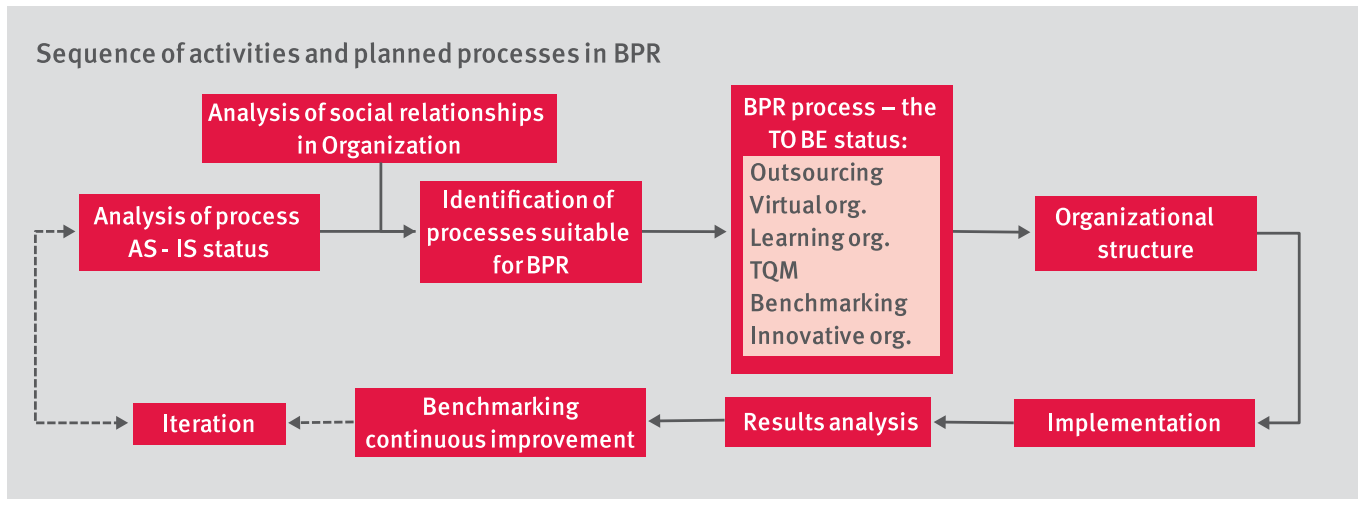

Figure 4: The Cyclical Structure of Reengineering

\subsection{Analysis and \\ Understanding of the Existing Process and Identification of the Problems}

Apart from the specification of the process itself, a profound understanding of the process is also necessary and a feeling for the fine details of production. It is necessary to understand the fine details of the process and analyse them, since the possibility of failure lies in the details. Through the analysis and specification of the process, the problems in production are identified. When it is a matter of processes from different segments of the company, they are grouped as such, where points are sought which comprise a cross-section of all the segments of the company. After the problems have been identified, it is necessary to understand why they occur and the environment in which they occur. The parameters of influence and size are found on which they depend, and they are analysed.

\subsection{Analysis of the \\ Sociological Parameters of the Company}

The readiness of employees to conduct the BPR process and the problems which may stem from that should not be overlooked. All modern concepts of business improvement place people/workers in the centre of attention. The basic problem that arises when introducing BPR is resistance from employees, and this mainly arises as a result of insecurity regarding their jobs and fear of redundancy, fear of the "new"/ "unknown", fear of loss of power and previous positions, individually oriented workers, the existence of informal groups etc.

For the sake of illustration, we will give an example:

The BPR process must be well-prepared, and to avoid risks the following are necessary:

- Thorough preparation of employees and avoiding the emergence of informal groups

- activities by team members on lower levels

- Inclusion of employees in the process to gain their confidence

- In this way creation of a "friendly" environment within production segments in the company.

- Individual contact with every employee in order to raise their motivation level

- Employee awareness of their own contribution and responsibility and the aims of production

- The managers need to be more like coaches and less like classical managers.

\subsection{Defining Business Processes suitable for BPR}

Since the BPR procedure, in terms of its main determinants, is thorough and radical, this means that practically the entire company will experience reorganization. The backbone of the changes is formed by the key processes of the company or the processes which have a strong influence on them.

The BPR process is conducted regarding the following processes in the organization:

- The sales process

- The marketing process

- The process of procurement and storage

- The complex process of in hall production (all production lines)

- The complex process on the building site (all processes on the building site, including assembly)

- The process of management of human resources (calculation, stimulation and monitoring employees)

- The process of technical preparation

- The process of management of business processes in the company

- The process of monitoring and control

\subsection{BPR of Selected Processes} The implementation of BPR only begins when the team managing the changes decides that the organization is ready for radical and thorough changes.

\subsubsection{The Sales Process}

The sales process overlaps to a large extent with the area of marketing. Apart from the standard well-established 
sales methods, through sales agencies or one's own sales, sales can also be organized through professional marketing agencies.

We note a problem which prevents many companies from reacting in good time to customers' queries, which is the time needed to draw up a quotation/estimate, which in the end, in view of the number of quotations that need to be drawn up, may result in significant costs. As a radical move and drastic change, the introduction of software is suggested, on the basis of a neural network (Kararić and Vukomanović, 2009). The organigram below shows the course of the sales process, before and after the reengineering procedure. which are: production of wall panels, production of precast elements of ceiling panels, and production of the precast elements of the roof structure. All these processes are key processes of the organization and the "core business " of the company. The quality of their performance determines the degree of competence of the company for these processes, or the company's ability. All the activities and processes related to the complex processes of production mentioned above may be divided into two groups: activities and processes of local importance, and activities and processes of strategic importance. a result. The optimization of these processes is a condition for improving the core business processes. How radical the intervention is here depends on the current status of the organization, but usually the greatest resistance is to be expected from employees. The characteristic activities and processes in this context are for example: the procurement process, continuity of production in the sense of the organization, aligning the production of precast elements, optimal organization of the space in the hall, production of precast elements with no faults, temporary storage of elements according to the assembly plan, loading elements onto a vehicle with all the necessary additional ma-

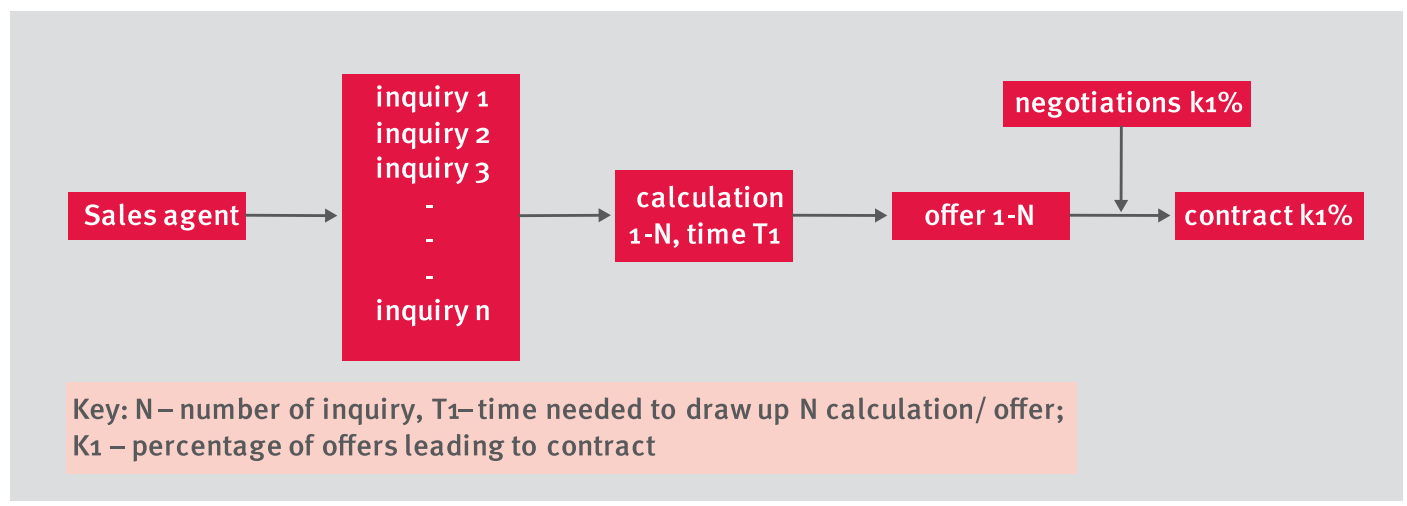

Figure 5: The Sales Process before the Reengineering Procedure

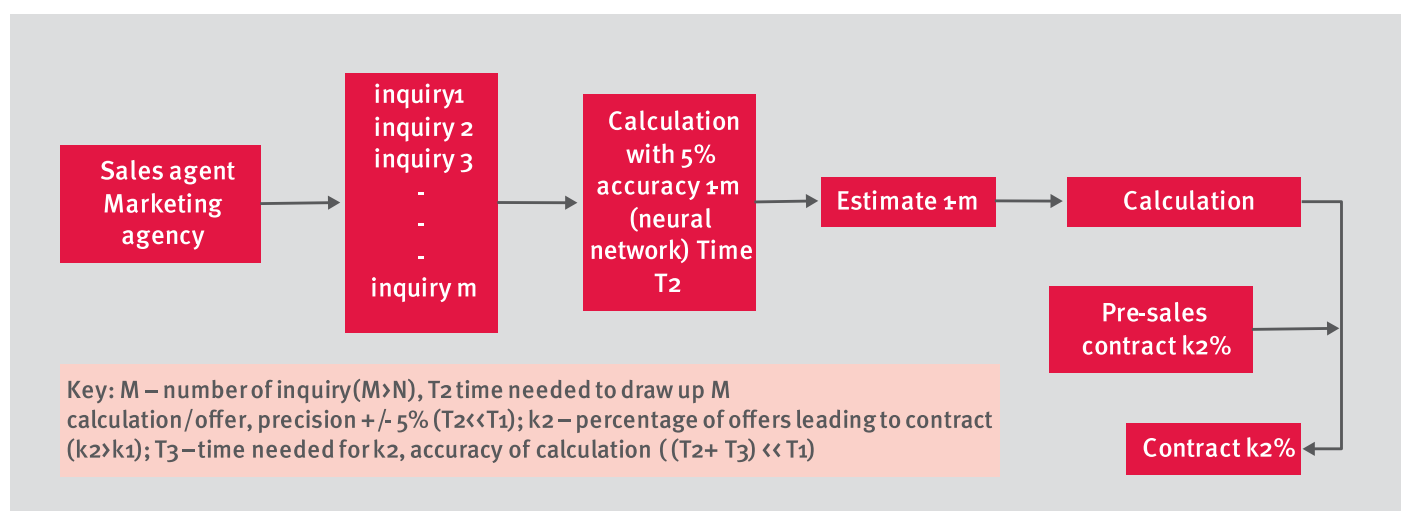

Figure 6: The Sales Process after the Reengineering Procedure

\subsubsection{The Complex Process of Production in the Hall (all production lines)}

The term "complex" here implies all the processes which take place in the production hall of the company,
5.4.2.1. Activities and Processes with Local Importance

The term "local" here relates to improving these processes which would be optimized in any organization, but they must not be neglected as terials, tools and equipment, reducing the costs of production and raising the attitude of employees to a level compatible with the modern concept of business improvement. 
5.4.2.2. Activities and Processes with Strategic Importance

This group of processes includes the core processes of the company arising from its basic competences. For a company that deals in the production and assembly of precast buildings, these are the processes that take place in the production hall, creating the finished elements of the agreed building.

The market conditions of the business and the pace of changes on the market have caused the creation of different organizational structures of companies. Regardless which type of organizational structure is in question, the company must retain its basic competences of production and assembly. However, the question arises of the stability of the company in extreme market conditions: a time of social prosperity in contrast to a time of economic crisis. The right response to that kind of challenge is found in Outsourcing or moving production elsewhere. Outsourcing is usual for non-core business. For a company dealing in precast building, limited outsourcing of core processes is recommended.

This form of outsourcing is suitable for the following reasons:

- It is possible to regulate the quantity of production depending on the market conditions

- It disperses business risk

- It is possible to increase capacity without special investment

- the tight relationship between outsourcer and the mother company

- It is possible to adapt quickly to market requirements

- Preservation of one's own competences in knowledge and production skills

A safe way of moving key production processes, whilst maintaining company stability, is outsourcing production whilst preserving one's own production lines. That is to say, any complete outsourcing of production necessarily leads to a loss of the competence (the main characteristics of the key processes) of the organization. In order to improve the production process, part of the production is outsourced which is beyond the capacity of the individual production lines in the hall. The company will retain one production line in full capacity for wall elements, panel elements and roof elements. All the remaining production volume will be outsourced, taking care not to mix projects together. In other words, it is a matter of parallel production.

For the company to implement outsourcing as a business method, it has to create an outsourcing strategy beforehand. The phases of the OS strategy are:

- Internal analysis and evaluation

- Analysis of the benefits of the business processes for OS

- Analysis of supply and choice of partners

- Choice of form of OS and implementation

- Management of OS process

Alongside the general strategy as the basic determinant of the development of the company, the analysis and conclusion to use BPR, a thorough analysis and evaluation is made of all business parameters. Apart from this, it is necessary to identify competitors and undertake comparative and SWOT analyses, with critical reference to the results of the comparison. The company, during the internal analysis, must answer the question, what is "currently" good and what is not good, and what needs to be changed and why? Moreover, it must make an analysis of the price of the product and understand the structure of the price and find parameters which may be changed and those which are fixed. Before deciding to introduce outsourcing, alternative solutions must be defined/stated and analysed.
On the basis of the analysis from the previous part, a strategic decision is made to apply outsourcing for key processes in the company (the complex production process), whilst completely recognizing the dangers and risks that follow this decision. The reengineering team concludes that it will undertake partial outsourcing of the core processes of production with the appropriate preparation. Since outsourcing is above all a matter of trust and reliability, which are characteristics relating to knowledge of the partners, it is vital to do thorough research into all potential candidates before any official invitation. For all new, unknown partn ers, a certain amount of time is needed for acquaintance, in order to gain an impression of the benefits. One of the possibilities is the development of a completely new company (outsourcer) tied to the outsourcing partner. The relationship founded in this way is stronger and more spontaneous that the relationship between two developed business entities. The weakness is of course the current lack of one's own market in the outsourcer's field, but the company is being founded above all for the needs of the outsourcing partner. It profits by receiving new technology, knowledge obtained over many years, support during production, becoming acquainted with and running in production etc., all of which is practically impossible to obtain under normal circumstances. Introduction of outsourcing is undertaken according to the following plan:

In the figure above, the concept of complete OS is related to the volume of production which is to be outsourced in the end. Preparation of the company is undertaken in line with the internal analysis and evaluation of the business processes. In this process, it is necessary to make some strategic decisions, such as for example the question of the volume of production being outsourced, as presented in de- 
Planned course of outsourcing

\section{Preparation}

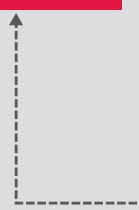

Backsourcing

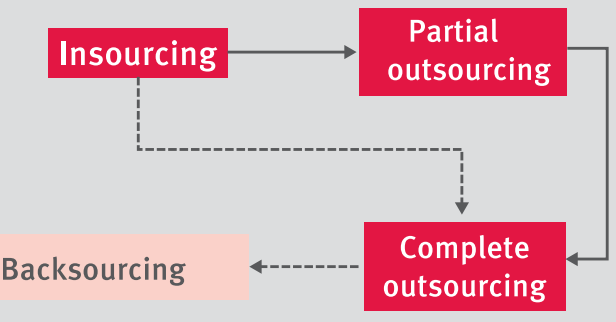

Figure 7: The Path of Development of Outsourcing in the Company

tail above. Bearing in mind the goal of OS, the company must critically answer the questions related to risks:

- What gives the company security during OS?

- What if a partner terminates the contract for any reason?

- What after OS?

- What about the knowledge and technology being transferred to the outsourcer?

I

nsourcing, as an interim phase before outsourcing, is introduced for the following reasons:

- Less risk in transfer

- Easing the "shocks" in an organizational sense.

- Giving the employees a chance to become accustomed to the new solutions

- Enables the outsourcer to attain the skills vitally necessary for production (education),

- Tests the IT solutions and communication

After successful implementation of insourcing, partial outsourcing follows. The partial nature is seen in the fact that the entire volume of production planned is not outsourced. That is to say, as a strategic move, the company decides that it will outsource processes, but the scope of the outsourcing will be only to the extent necessary to retain the company's security and stability.
For OS to be successful, it is necessary to transfer all the company's necessary knowledge and skills to the outsourcer, or, at best, it is necessary to align them. For the outsourcer to satisfy the demanding criteria of the final product, they must be acquainted with all the standards, norms and other requirements of production, even the construction and legal regulations covering this area. The best way to attain this very demanding goal is to train the outsourcer's work force in the production hall of the company doing the outsourcing. After implementation of OS, it is necessary to monitor the process constantly in line with the precautions given above.

\subsubsection{The Complex Process on the Building Site}

If we set aside the activities related to provision of infrastructure, coordination of the participants in construction and partial assembly, all the other processes in the existing situation have already been entrusted to other contractors. The basic reason is that these processes, in terms of their special character (arising from the construction material), are so different from each other that it is very difficult to coordinate all the skills in one organization for both forms of construction. Therefore organizations dealing with this type of precast building as a rule do not undertake (should not undertake) reinforced concrete, brick laying and similar work themselves.
In the table below a presentation is given of the current situation and possible improvements, according to the various processes.

\subsubsection{The Process of Technical Preparation}

This is one of the core processes of the company. The diagram below of the technical preparation process has been drawn up according to the planned status.

This form of organization of the technical sector offers the possibility of production with minimal faults and discontinuity. The process of creating workshop plans is subject to the same consideration as the complex processes of production in the hall. This is also a key process of a company of this nature and its outsourcing necessarily leads to major risks. If those risks are successfully controlled, the company is able to outsource the process of creation of workshop plans.

\subsubsection{The Process of Monitoring and Control}

There is no separate organizational unit dealing with monitoring and control. This group of activities is accompanied by procedures, check lists, information from various phases of the realization of the project etc. which are all distributed in the form of feedback information to various working points of the elaborated project. However, there is a process, which as such permeates the various segments of project realization and it is implemented by the teams (heads of teams) of the individual functional units. For example, this includes systematic monitoring of production and gathering data which is later analysed. On the basis of the data collected, the company may realize multiple benefits:

a) On the basis of feedback information, faults in production can be corrected. 


\section{Technical Preparation}

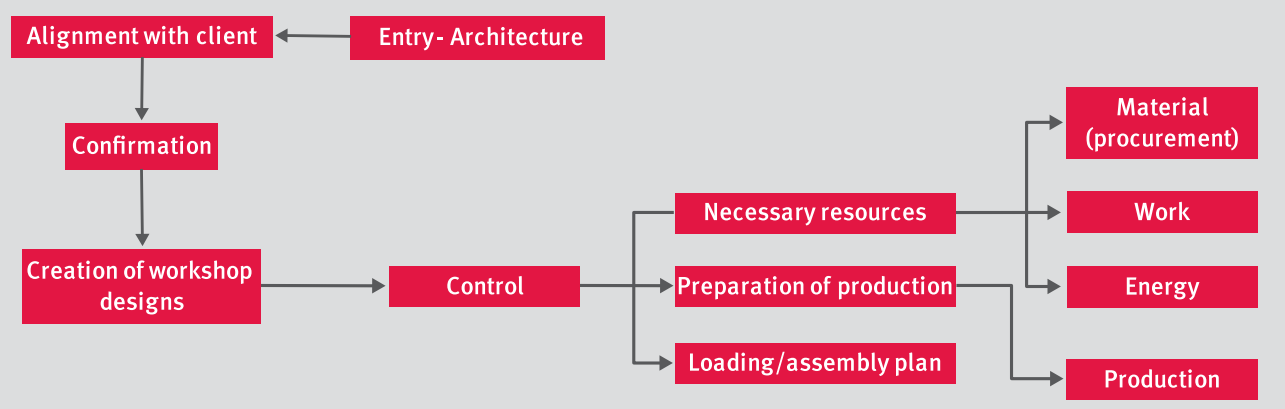

Figure 8: Organization Chart of the Process of Technical Preparation

b) Better solutions are introduced (technical, expenditure, organizational, functional...)

c) By gathering data, over the course of time the company creates an exceptionally valuable data base. d) The process of monitoring and control is a tool in the hands of the head for maintaining production quality.

The following plan gives a presentation of the critical points in the pro- cess of monitoring and control. The figure below gives a schematic presentation of after and before the reengineering process.

Flow chart of redesign process of monitoring and control

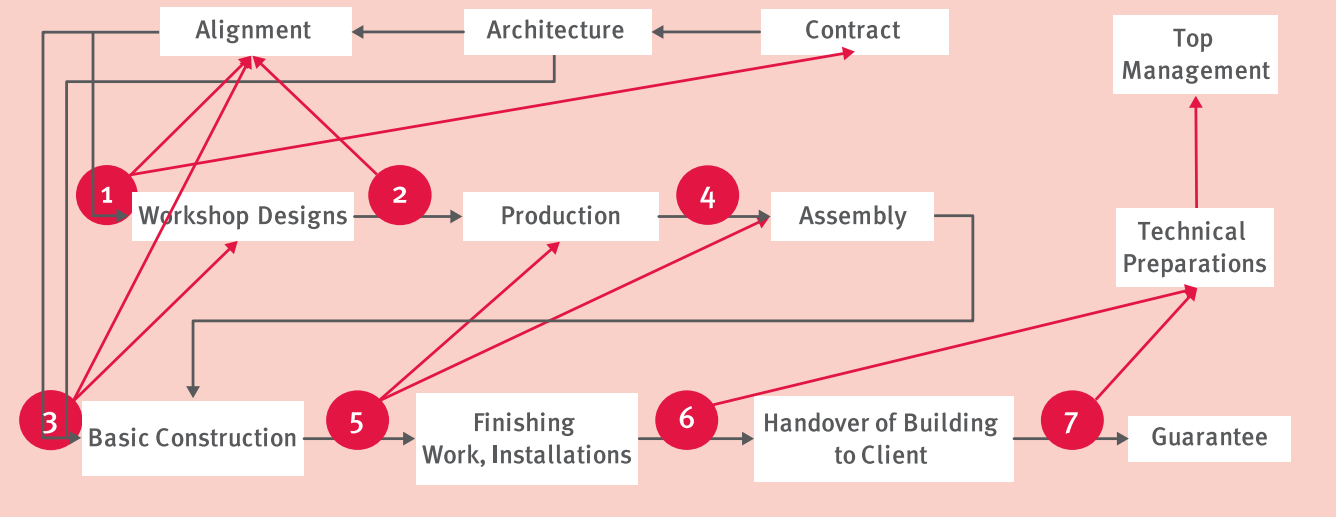

Figure 9: The Process of Monitoring and Control after Reengineering

Flow chart of existing process of monitoring and control

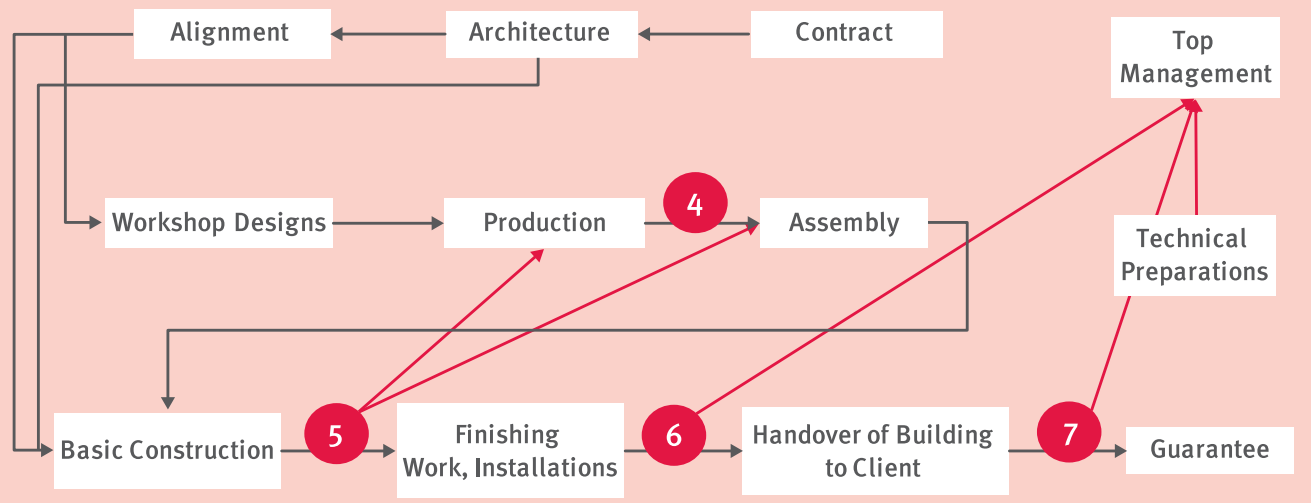




\subsection{The New Design of the Organizational Structure of the Company}

On the basis of all the above, redesign of the organizational structure of the company is undertaken, where the redesign is based on the main determinants from the concept for improving the business processes explained above.

Since organizations dealing in construction are project-oriented, the organization/company considered is also a project-oriented organization. This orientation is defined by the contract on the planned subject of construction, the time of construction, the price and the quality required. In contrast to classical construction, where the construction work takes place at only one location, precast building is characterised by at least two points of construction: the building site and another construction location, that is, the plant for producing precast elements. The aim of each company is to attain continuity of production in the organizational unit dealing with production of precast elements, in order to prevent hold ups in production.

The organizational structure of the company should be considered above all on the level of a project, but the characteristics of production should not be overlooked. On the basis of the consideration so far, it may be said that these are two equally valuable processes in the company. They take place according to their own rules, and the task of the management structure of the company is to align them. The schematic relationship of production and the project, all within the company, may be presented as in the figure below.

This model relates to a single production line and encourages continuity of production. A company with greater capacity and marketing, which enable it to have sufficient sales, has a layered structure like this. This scheme

The Company Structure based on the Project - Production Relationship

The Company

Project 1 Project 2 Project 3

Project $n$

Production of wall elements

Production of ceiling elements

Production of roofing elements

Production of otherprecast elements

\section{Figure 11: The Relationship of the Project and Production in the Company}

assumes that the building site ("Complex processes of construction") is an integral part of the project, and is not shown separately.

According to all the above, the optimised organizational structure, after reengineering is as follows: the environment within which they should take place. The three units of the company are clearly expressed: technical preparation, production and the building site. The emphasis on these three organizational units does not mean that for example the sales

Organizational Structure based of a Precast Building Company

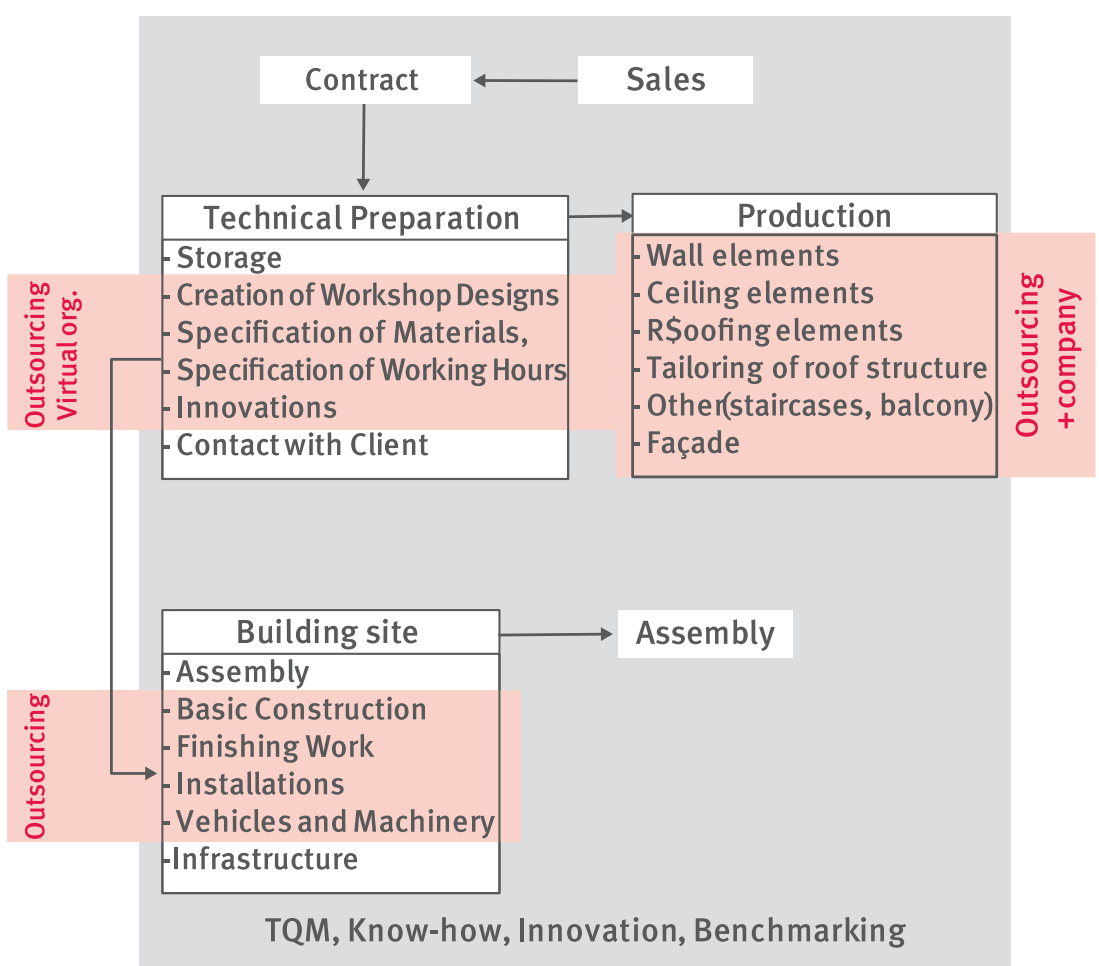

Figure 12: Proposed Organizational Structure of the Construction Company Dealing with Precast Houses

This is a very generalized presentation of the structure. The structures of individual processes shown earlier is an integral part of this structure. The plan shows the basic processes and process is less important. The sales process is simply a separate activity which, in a technical and technological sense, is not connected with the other units. Alignment of these three 
units will lead to optimal production and realization of all the obligations of the projects taken on.

From the plan it may be seen that the company is organized on the principle of outsourcing and that it operates in an environment and on the basis of the principles of TQM, learning and innovative organization, and Benchmarking. The plan shows the processes which are outsourced, and the manner of outsourcing is given above. The precaution is pointed out in particular that the part of production is outsourced for which the company does not have sufficient capacity of its own. The company's capacities should be sized according to the capacity of the production line for each individual type of precast element: wall panels, ceilings, roof etc.

\subsection{Implementation of BPR}

After all the preparations have been conducted, implementation of the planned improvement measures begins. In implementation, it is necessary to pay attention to all the potential and real risks presented for each individual concept of improvement. Here the most important thing is to maintain the process character of production, which primarily means the awareness of all co-workers that a complete structure is being produced (a building), and not a single wall, one ceiling element or only a roofing element.

\subsection{Analysis of Results}

During the implementation of the procedure, it is necessary to monitor the procedure regularly and constantly, gather data, analyse them and then draw conclusions. The process of monitoring and timely analysis of events is exceptionally important. Here it is important to point out that the team managing the BPR must have the appropriate competences, so that they are able to identify not only negative trends, but also any signs, or a trend of unfavourable movements.

\subsection{The Use of Benchmarking as a Method of Continuous Improvement}

Benchmarking is a tool for continuous improvement of business processes. Benchmarking provides real data about the company's position on the market. Any other way of probing the market produces only an assessment; Benchmarking gives information on the real situation. It is one way the improved processes may be subjected to iteration, if the level of improvement is not satisfactory, or even for maintenance of a competitive advantage on the market through the process of continuous improvement.

\subsection{Decision to Repeat the Procedure}

The company's top management, in cooperation with the team managing the $B P R$, renders a decision on the need for iteration of the BPR procedure. Iteration depends on the level of process improvement attained, but in the introduction we mentioned that BPR is a radical and thorough process. If the process is conducted correctly (multi-disciplined), the expected improvement is between 30 and $35 \%$. This percentage may relate to any relevant business parameter. If this percentage is not achieved or there is any significant deviation this would mean failure.

\section{Conclusion}

This study deals with the issue of business process reengineering in an organization producing precast buildings, and optimization of its business processes. It does not go into the explicit details of the organization of production, design and dimensions of the production line, warehousing, lines of communication etc. Although these are issues which are extremely important for the success of a specific process, they are of a technical nature, and as such are not decisive for the question set. The modern concepts of business considered here differ basically only in terms of the elements of the process on which the focus is placed. Here they may be divided into two groups:

\section{- concepts that affect the design of the organizational structure and \\ - concepts that lead to increasing the competitiveness of the company, without intervention in the organizational structure}

In the first case, this is a matter of, for example: outsourcing, TQM, virtual organization etc. The solutions that arise within these concepts must be implemented through the organizational structure of the company as well. The second group includes for example: Benchmarking, innovative organization, a learning organization etc. Implementation of the solutions of these concepts requires activities whose only goal should be designing the "organization consciousness" on an ever-higher level.

The application of all modern concepts, with the appropriate team concept of work, leads to a good possibility of improving the business processes of the organization. Here it is very important to "remain alert", that is, continuously to monitor events in the organization and react in good time, since this is the best way to respond to the demands of the market today.

\section{References}

Bourquin, T. (1998) Global Software Development: Offshoring vs.

Outsourcing, Institut für Informatik im Fach Wirtschaftsinformatik.

Bundesverband Deutscher Fertigbau (2010) Wirtschaftliche Lage der deutschen Fertigbauindustrie, (http:// www.bdf-evde/german/verband/ wirtschaft/index.html)

Diederichs, C.J. (1996) Handbuch der strategischen und taktischen Bauunternehmungfuehrung, Bauverlag. 
Girmscheid, G. and Schulte, M. (2000)

Outsourcing als Bestandteil der strategischen Unternehmungsplanung von Bauunternehmen,

Unternehmensplanung, Kooperation, Baubetrieb - Band 75.

Hammer, M. and Champy, J. (1993) Reengineering the Corporation: $\mathrm{A}$ Manifesto for Business Revolution, Harper Collins.

Kararić, M. (2011) Reengineering of Timber Houses Construciton Process, Master theses, Faculty of Civil Engineering, University of Zagreb.

Kararić, M. and Vukomanović, M. (2009) Model for cost prediction of prefabricated housing. Tehnički vjesnik Vol. 16. No. 3, pp. 39-43
Paim, R.; Caulliraux, H.M.; Cardoso, R. (2008) Process management tasks: a conceptual and practical view, Business Process Management Journal, Vol. 14 No. 5, pp. 694-723

Peters, T. and Waterman, R.H. (1982) In search of excellence, Harper and Row.

Pfenning (2005) Innovative Konzepte der Wirtschaftsindustrie.

Presber, R. and Ulitzsch, R. Erfolgsfaktoren von Bauunternehmen, Pericon, Unternehmensberatung, (http:// www.pericon.de/downloads/de/ Erfolgsfaktoren-von-Bauunternehmen.pdf Schmitt, K. Outsourcing ermöglicht den Arbeitsplatz der Zukunft, (http://www.silicon.de/cio/ strategie/o,39038989,39187046,oo/out sourcing+ermoeglicht+den+arbeitsplatz +der+zukunft.htm)

Thom, N. and Etienne, M. (2001) Business reengineering, Lexikon des Qualitaetsmanagements, Oldebourg Verlag.

Walter, N. (2006) Auswirkung der Gobalisierung auf die Bauwirtschaft, 62. Euroconstruct-Konferenz.

Weber M. H. (2002) Measuring supply chain agility in the virtual organization, International Journal of Physical Distribution \& Logistics Management, Vol. 32, No. 7, pp. 577-590 